\title{
CONVENTIONS USED IN THIS BOOK
}

As far as possible, the jingles reproduce the sounds and stresses of the Portuguese words. Three Brazilian sounds require special treatment: 1) nasalized vowels and diphthongs; 2 ) $\mathbf{r}$ in certain combinations; 3 ) $s$ in certain combinations. These are explained below:

1. In Portuguese, vowels and diphthongs can be either plain or nasalized. A nasalized vowel is produced when air is allowed to resonate in the nose as well as in the mouth. Example: plain vowel, moo; nasalized vowel, moon. Portuguese nasalized vowels and diphthongs are more highly nasalized than nasalized sounds in English.

In this book a nasalized vowel is indicated by an italicized $\boldsymbol{m}$ or $\underline{n}$ following the vowel. These italicized letters are not pronounced. Example:

mundo

earth, world

Look at the moon. Do you know why It follows the earth around the sky?

The sound of mundo is given by the moo of moon plus Do. In this book the italicized $\boldsymbol{n}$ is simply a signal that the oo of moo is to be nasalized. (In certain words, such as mundo, a faint suggestion of an $\mathbf{n}$ can be heard in the background.) 
2. The $r$ between vowels or in consonant clusters (pr, br, $\mathrm{dr}, \mathrm{tr}, \mathrm{cr}, \mathrm{gr}, \mathrm{fr}$ ) has the sound of the tt, in American English potty. Here is an example:

choro weeping, sobbing (n.)

The show routinely ends with weeping, At least for all who still aren't sleeping.

The sound of the Portuguese word is captured by the word show followed by the rou of routinely. As the rule just given requires, the $r$ in choro is pronounced like the $t \underline{t}$ in potty. This $r$ is left unmarked.

When $r$ is not between vowels and is not in a consonant cluster it has the sound of a highly exaggerated $\mathbf{h}$ (approximating the Spanish $\mathrm{j}$ ). In this book this sound is indicated by an italicized $\underline{r}$ in bold print. Here is an example:

roubar to rob

You must probe Arthur's links with crime. He robbed his Ma of her last dime.

The sound of roubar is built up from the sound of robe in probe plus Ar of Arthur's. Both the initial and the final $\underline{r}$ of roubar have the sound of a highly exaggerated $\underline{h}$.

3. The letter $\mathbf{s}$ has several sounds in Carioca Portuguese, depending on its environment in a word. Before the sounds $\underline{p}, \underline{t}$, $\underline{k}$, and at the end of a breath group, $\mathbf{s}$ has the sound of sh in shirt. In this book the sh sound is represented by an italicized $s$. Here is an example:

bispo bishop

Bee, spoon out some applesauce;

The Bishop lost his dental floss! 
In this jingle, the sound of the Portuguese word is captured by the underscored syllables. As was noted above, the italicized s is pronounced like the sh in shirt.

For a more extensive view of the sounds of Carioca Portuguese, refer to the pronunciation guide in the Appendix.

\section{OTHER CONVENTIONS}

1. The main Portuguese entry always gives the infinitive of verbs and the singular of nouns. The pronunciation demonstrated in the jingle applies to these basic forms. In the jingle the English equivalent of the Portuguese entry may appear in any convenient form. For example, a verb may be in any tense, and a noun may be either singular or plural.

2. The gender of nouns is given except for nouns ending in o (which are usually masculine), or in a (usually feminine). Endings in 0 and a are given for adjectives that indicate gender by these vowels.

3. In the jingles, a long dash [-] may indicate a change of speaker. 
THIS PAGE INTENTIONALLY LEFT BLANK 